DOI 10.37882/2500-3682.2021.08.17

\title{
АРМАС ОТТО ВАЙСЯНЕН И РОБЕРТ ЛАХ - ОСНОВНЫЕ АСПЕКТЫ АНАЛИЗА МАТЕРИАЛА ПО МОРДОВСКОМУ МУЗЫКАЛЬНОМУ ФОЛЬКЛОРУ
}

\section{ARMAS OTTO VYAYSYANEN AND ROBERT LACH - THE MAIN ASPECTS OF THE ANALYSIS OF THE MATERIAL ON MORDOVIAN MUSICAL FOLKLORE}

E. Modina

Summary: Armas Otto Vaisyanen was born in Savonranta (Finland). Studied at the University of Helsinki. Has the title of Master (1919), Doctor of Science (1939), Professor. He is a collector and researcher of Finnish folk music and traditional music of other Finno - Ugric peoples, who is considered a classic in his field. This person is one of the few outstanding figures who worked with traditional folk vocal and instrumental recordings of the late 19th - early 20th centuries. His many field studies have resulted in about 6,000 tunes, surpassing all the achievements of earlier collectors. Väisänen became known to the general public as a connoisseur of Finnish folk music and the Karelian language. His works made a great contribution to the study of different national cultures. Together with professor, Dr. Robert Lakhs, he goes on an ethnographic expedition to the Mordovian villages. On the basis of the collected material, Vaisyanen published the book «Mordwinische melodies», which opens the curtain of the musical picture of the world of the Mordovians - Erzya and Mordovians - Moksha of that time for modern folklorists. In this work, traditional Mordovian songs recorded in 1914 are transcribed. These unique records were published in 1948 by the Finno - Ugric Society in Helsinki. Besides the book version, there is also audio material. The whole uniqueness of this work lies not only in the notated version of musical samples, but also in the opportunity to hear the true performance of the bearers of traditional culture. This makes it possible for modern researchers to have a more complete understanding of the Mordovian traditional musical culture and to hear the characteristic manner of singing characteristic of the Mordovians of that time.

Keywords: folklore, traditions, researcher, folklorist, ethnographer, musical - song, traditional, Vaisyanen, Finno - Ugric, Mordva, Erzya, Moksha.

\author{
Модина Екатерина Олеговна \\ Преподаватель, Мордовский государственный \\ университет им. Н.П. Огарева, г. Саранск \\ folk-katj@mail.ru
}

Аннотация: Армас Отто Вайсянен родился в г. Савонранта (Финляндия). Учился в Хельсинском университете. Имеет звание магистра (1919), доктора наук (1939), профессора. Он является коллекционером и исследователем финской народной музыки и традиционной музыки других финно-угорских народов, который считается классиком в своей области. Этот человек один из немногих выдающихся деятелей, который работал с традиционными народными вокальными и инструментальными записями конца XIX - начала XX века. Результатом его многочисленных полевых исследований стало около шести тысяч мелодий, превосходящих все достижения более ранних коллекционеров. Вяйсянен стал известен широкой публике как знаток финской народной музыки и карельского языка. Его труды внесли большой вклад в изучение разных национальных культур. Совместно с профессором, доктором Робертом Лахом он отправляется в этнографическую экспедицию по мордовским селам. На основе собранного материала, Вайсяненом выпускается книга «Mordwinische melodies», которая открывает завесу музыкальной картины мира мордвы - эрзи и мордвы - мокши того времени современным фольклористам. В данной работе расшифрованы традиционные мордовские песни, записанные в 1914 году. Эти уникальные записи опубликованы в 1948 году финно-угорским обществом в г. Хельсинки. Кроме книжной версии существует также аудио материал. Вся уникальность данной работы заключается не только в нотированной версии музыкальных образцов, но и в возможности услышать подлинное исполнение носителями традиционной культуры. Это дает возможность современным исследователям иметь более полное представление о мордовской традиционной музыкальной культуре и услышать характерную манеру пения, свойственную мордве того времени.

Ключевые слова: фольклор, традиции, исследователь, фолклорист, этнограф, музыкально - песенный, традиционный, Вайсянен, финно-угорский, мордва, эрзя, мокша.
$\mathrm{M}$ узыка мордвы, численно - крупнейшего из финско-угорских народов, базирующихся в Восточной России, до сих пор известна и изучена лишь в небольшой степени. Сборник А.А. Шахматова «Мордовский этнографический сборник» (Санкт-Петербург, 1910) содержит 53 вокальные мелодии, которые были собраны и записаны мордовским ученым Р.Ф. Учаевым в деревне Сухой Карбулак [2]. Этот материал впервые проанализировал князь Н. Трубецкой в своей статье «О структуре мордовских мелодий» [3]. Статья представляет собой приложение к «Песнопениям русских военнопленных»: «Мордовские песнопения» (Вена, 1933) профессора Роберта Лаха [10]. Летом 1917 года Лах записал 71 мелодию, услышанную от восьми военнопленных, находящихся на территории Австрии [14]. Из военнопленных 5 были родом из Самарской губернии, 1 - Нижего- 
родской губернии и 1 - Пензенской губернии, в то время как родина восьмого не указана. 24 мелодии были записаны на мокшанском языке, остальные - на эрзянском.

В то время, Вайсянен тоже был заинтересован работой Роберта Лаха. Благодаря стипендии Финско-угорского общества и помощи профессора Хейки Пассонена лучшего знатока мордовской поэзии и фольклора, была организована экспедиция в губернии, населённые мордвой, однако начало Первой мировой войны сделало невозможным полностью осуществить поездки. Вайсянену и Лаху удалось побывать лишь в двух уездах Самарской губернии (ныне Куйбышев), а именно в округах Бугуруслан и Бугульма, и в том числе в следующих деревнях: Эрзянский Бруслан, Пронькино, Середнёвка, Борискино, Од-Шантала и Вечканово. В этих сёлах (кроме Пронькино) проживали в основном мокшане, эмигрировавшые из Пензенской губернии около полувека назад.

Из привезенного материала, включающего около двухсот образцов песен и инструментальной музыки, большая часть состоит из хоровых песнопений. С помощью фонографа ноты было легко подобрать и записать, но особые трудности здесь представляли тексты песен, потому что Лах не был знаком с мордовским языком. Профессор на месте пытался вместе с певцами, слог за слогом, писать слова к мелодиям. Созданные таким образом тексты были изучены, исправлены и дополнены профессорами Пааво Равила и его учеником Кайно Хейккиля, хотя некоторые незначительные неясности всё же остались и по сей день.

Из сборника Шахматова «Мордовская народная поэзия» уже видны различные жанры песен. Для каждой мелодии, насколько это возможно, указано, к какому роду песни принадлежит соответствующая мелодия. Тексты мелодий содержат различные жанры песен: многочисленные баллады, некоторые повествовательные (исторические) песни, а также рекрутские песни, множество лирических песен. Среди них есть песни, представляющие собой наиболее примитивные музыкальные конструкции, например - песни, направленные против невесты и девушки в исполнении хора, песни, которые поются от лица невесты. Все жалобные песни, исполняют женщины. Они поются сольно, например, колыбельные. С другой стороны, для большинства других песен не имеет значения, поет ли их один человек или хор. Таким образом, многие из песен, предназначенные для одного человека, также могли быть спеты и хором, если это было необходимо.

Анализируя сборник «Mordwinische melodies» [1], выпущенный А.О. Вайсяненом по материалам этих экспедиций, у мордвы встречались либо мужские, либо женские ансамбли. Смешанных ансамблей не было. Принадлежали ли к женскому коллективу только девушки или за- мужние женщины, было совершенно неважно. В каждом ансамбле, где меняется количество певцов, есть запевалы. Они обычно должны быть лучше всего знакомы с текстом. По всей видимости, мордва переняла обычай петь в ансамбле у русских. На это указывает то обстоятельство, что русские песни, которые были записаны в фонограф для сравнения, имеют тот же стиль и поются в пентатонику. Несмотря на размер ансамбля, в мелодиях редко встречается более двух мелодических линий, всё поётся в интервал «секунда».

В инструментальных мелодиях данного сборника представлены два духовых инструмента, а именно длинная флейта под названием «вешкема», (по-русски «дудка», изготовленная из стебля растения), и примитивная двойная флейта под названием «нюди», обе трубки которой снабжены отверстиями таким образом, что один и тот же палец закрывает два отверстия одновременно. Трубы соединяет рожок, усиливающий звук.

Щипковые и струнные инструменты, как гусли и скрипки, были довольно редки; напротив, гармоника выполняла услуги танцевальной музыки в каждой деревне, как и в других местах России.

В своей публикации «Вогульские и восточноякийские мелодии» профессор следовал системе, которую более подробно обосновал во введении к работе.

Включение мордовских мелодий в эту систему вызвало некоторые трудности: при различных повторениях одной и той же мелодии происходит изменение как количества тактов, так и тактовой частоты. Мелодии могут быть родственны, хотя по форме и ритму они принадлежат к разным категориям; теперь, размещая очевидные варианты близко друг к другу, профессор вынужден был отклониться от следования своей системе.

Мелодии пишутся таким образом, что строка или пара строк поставлены на одну линию, а в повторениях соответствующие друг другу строки, по возможности, находятся в одном и том же месте страницы. Границы строк задаются толстой тактовой чертой. На различных строках есть буквы (А, В и т. д.). Цифры рядом с ними (например, А4) указывают на числовое число строк. Если буквы не указаны рядом с цифрами, то мелодия является регулярным образцом группы.

Многочисленные мелодии вызывали трудности анализа, с одной стороны - при определении границ, с другой - при определении их разности, поэтому текст часто не совпадает с мелодической строкой. Нечёткое следование певцом метроному, который может казаться ровным во время прослушивания, нарушается дополнительными добавленными гласными, слогами и словами. Они заключены в круглые скобки в публикации, а также 
есть вопросительные знаки, обозначающие необъяснимые фрагменты текста.

Круглые скобки вокруг нот указывают на то, что автор считает соответствующие звуки избыточными, возникающими в связи с передышкой в середине строки. Эти звуки, а также зажатые паузы, не учитываются при расчете тактов.

Квадратные скобки вокруг нот и пауз обозначают дополнения редактора для достижения регулярности мелодии. Когда размер такта нарушается, конец тире на линейной системе указывает предполагаемое место звука. Нота, заключенная в скобки рядом с ферматой, указывает относительную продолжительность звука. Хотя фермата написана по системе нот в хоровых песнопениях, она относится и к другим певцам, также продолжительность ферматы не одинакова для всех.

В метрономе иногда есть два номера, чтобы показать, что темп увеличивается с продолжительностью пения $(>)$.

Рядом с метрономом в круглых скобках показана абсолютная высота тона мелодии (например, а). В двухголосных случаях, например, такая пометка, как «g1=h1», показывает, что g1 соответствует написанной мелодии в исходной лекции $\mathrm{h} 1$.

Для облегчения сравнения, из мелодий, мажорные обычно пишутся в «G», минорные в «е» и плагальные в «а». Знак увеличения установлен в угловой зажим ['] для восприятия в мажоре. Знак перед нотой вертикальный крест (+) обозначает увеличение примерно на 1/4 уровень звука, знак $d$ - понижение, примерно на $1 / 4$.

В ансамбле, в некоторых случаях, когда линия трех голосов четко выражена в прослушивании фонограммы, применяются две нотные системы.
Во избежание ненужного расширения мелодии, написанной после образцов, показано, каким образом определяется определенное её место (например, I) или 2), соответственно).

Содержание дает краткий анализ каждой мелодии:

1. Количество строк (I, II и т.д.);

2. Число тактов: 2 строки - считается по 2; 4 строки - считается по 4; 4, 6 строк - 4 и 6 (считается по 2+2+4); 6 строк - (считается по 2+2+2); 3 строки считается по 3; 5 строк - считается по 5;

3. Тактовый режим: Т2 = прямой такт; Т3 = трехчастный такт; Т5 = пятичастный такт; Т6 = трехчастный такт; 3 T2-трехсторонний такт; Tvr - такт соединения или свободные тактовые режимы: Tvr (varius regularis) = регулярный, Tv. (varius irregularis) $=$ нерегулярный.

При обозначении, арабские цифры (2 3,4 и т. д.) указывают тон выше основного тона, латинские - тон ниже того же (VII ведущий тон и т.д.). В скобках стоят цифры, обозначающие нисходящий тон, который может появиться совершенно случайно в одной мелодии. В пентатонической мелодии: если в мелодии стоят четыре различные строки, кроме того, все - четырёхчастные. Это - подлинный пентатонический минорный пентаккорд, поэтому результат этого анализа можно проиллюстрировать краткой формулой: IV (ABCD) 4 T2 минорный.

Этот сборник представляет собой сокровищницу мордовской народной музыкальной культуры. Его уникальность позволяет воссоздать аутентичные образцы мордовской народной песни в первозданном её виде. Секундовое звучание, характерное для мордвы - эрзи и мордвы - мокши, услышанное в реальном времени, позволяет прочувствовать те эмоции и чувства, которые испытывали исполнители.

\section{ЛИТЕРАТУРА}

1. Вяйсянен A.0. Mordwinische Melodien // Suomalais-ugrilainen Seura. - Хельсинки, 1948.

2. Мордовский этнографический сборник: в приложении: Описание села Оркина Сарат. уезда А.Н. Минха / составлен А.А. Шахматовым. - С.-Петербург : Тип. Имп. Акад. наук, 1910. - 848 с.

3. Трубецкой Н.С. К структуре мордовских мелодий //Избр.тр. по филологии. IL, 1987. С. 391-406.

4. Х Хайкки Паасонен: Die türkischen Lehnwörter im Mordwinischen // JSFOu XV. Helsinki, 1897.

5. Хайкки Паасонен: Die soqenannten Karataj-Mordwinen oder Karatajen // JSFOu XXI. Helsinki, 1902.

6. Hornbostel E., Sachs C. Systematik der Musikinstrumente // Zeitschrift für Ethnjljgie. 1914. № 46. S. 553-590.

7. Krohn I. Welche ist die beste Methode, um Volks und Volkasmässige Lieder nach ihrer melodischen (nicht textlichen) Beschaffenheit lexikalisch zu ordnen // Sammelbände der Internationalen Musikgesellschaft. 1903. Hb. 4. S. 643-660.

8. Lach R. Die Musik der turk-tatarischen, finnisch-ugrischen und kaukasus-völker in ihrer entwicklungsgeschischlischen und psychologishen Bedeutung für die Entstehung der musikalischen Formen // Mitteil. der Anthropol. Ges... Wien, 1920. Bd. 50.

9. Lach R. Gesänge russischer Kriegsgefangener. I Band: Finnisch-Ugrische Völker. 1 Abteilung: Wotjakische, syrjänische und permiakische Gesänge. Wien; Leipzig, 1926. 
10. Lach R. Gesänge russischer Kriegsgefangener. I Band: Finnisch-Ugrische Völker. 2 Abteilung: Mordwinische Gesänge. Wien; Leipzig, 1933.

11. Lach R. Gesänge russischer Kriegsgefangener. I Band: Finnisch-Ugrische Völker. 3 Abteilung: Tscheremissische Gesänge. Wien; Leipzig, 1929.

12. Lach R. Vorläufiger Bericht über die im Auftrage der Kais. Akademie der Wissenschaften erfolgte Aufnahme der Gesänge russischer Kriegsgefangener im August bis October 1917. Wien, 1918.

13. Szomjas-Schiffert G. Geschichte und Ergebnisse der finnisch-ugrischen vergleichenden Volksmusiktotschung // Congressesus Quartus internationalis fennougristarum. Budapest, 1975. Pars 1. S. 141-158.

14. Tari, L. (1988). Robert Lachs Postkarten im Handschriftenarchiv der UAW. Studia Musicologica Academiae Scientiarum Hungaricae, 30(1/4), $297-302$.

15. Trubetzkoi N. Über der Struktur der mordwinischen Melodien // Lach R. Gesänge russischer Kriegsgefangener. I Band: Finnisch-Ugrische Völker. 2 Abteilung: Mordwinische Gesänge. Wien; Leipzig, 1933. S. 106-117 [Приложение].

16. Vikar L. Arhaic Types of Finno-Ugrian Melody // Studia Musicologica Academiae Scientiarum Hungaricae. 1972. № 14. S. 53-91.

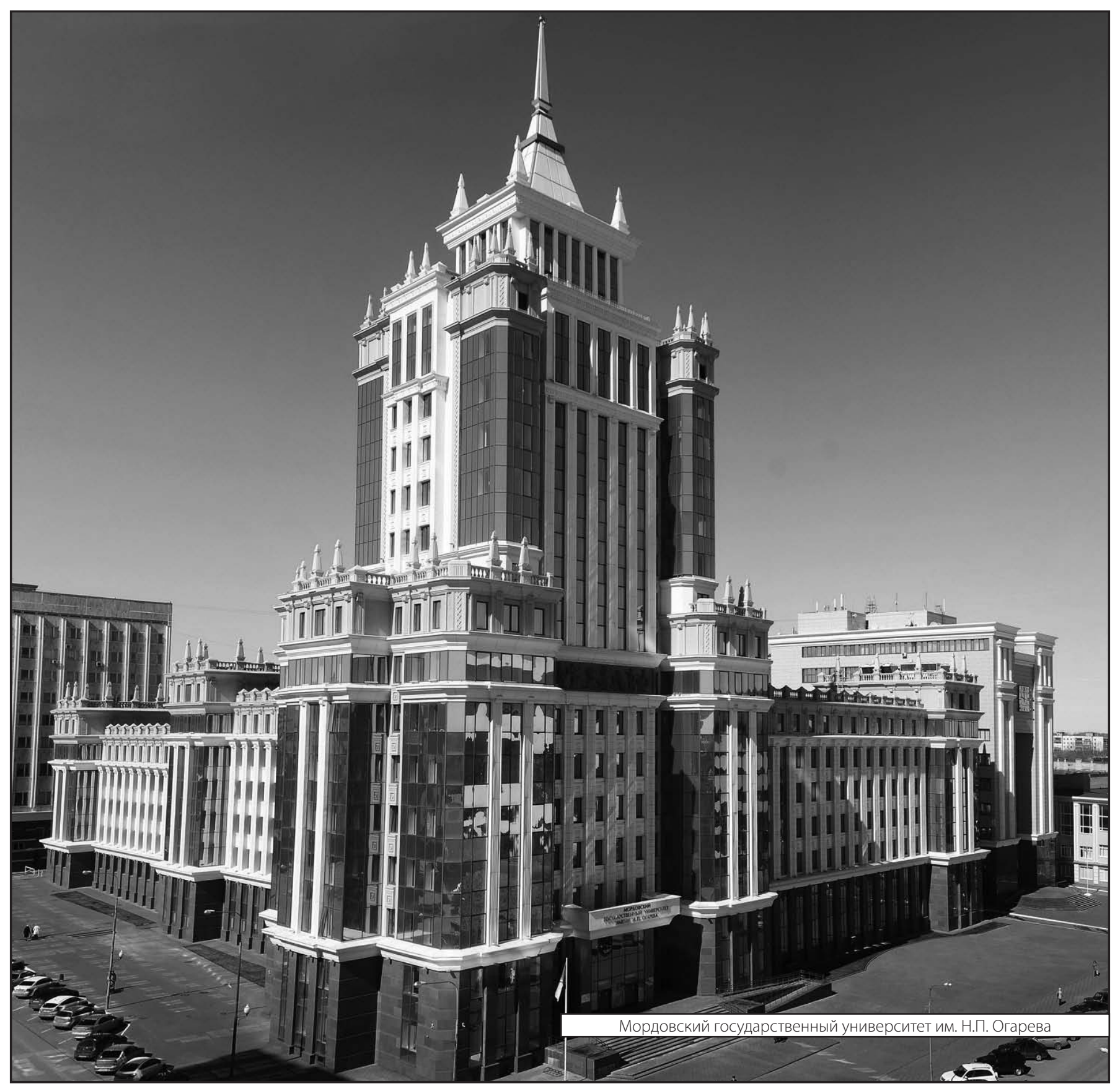

